\title{
Forced Displacement and the Plight of Internally Displaced Persons in Northeast Nigeria
}

\author{
Nasa'i Muhammad Gwadabe ${ }^{1}$, Mohd Afandi Salleh ${ }^{1}$, Abdullahi Ayoade Ahmad ${ }^{1}$ \& Sobia Jamil ${ }^{1}$ \\ ${ }^{1}$ Department of International Relations, Faculty of Law and International Relations, Universiti Sultan Zainal \\ Abidin, Malaysia \\ Correspondence: Nasa'i Muhammad Gwadabe, Department of International Relations, Faculty of Law and \\ International Relations, Terengganu 21300, Malaysia. Tel: 60-1133-221-380, 234-8065-655-255. E-mail: \\ ngwadabe@gmail.com
}

Received: May 24, 2018; Accepted: June 17, 2018; Published: June 20, 2018

\begin{abstract}
Since the end of the Cold War, the phenomenon of forced displacement gained more global attention. Forced displacement involves the involuntary movement of people from their habitual place of residence to a location within their country of nationality; or across an internationally recognised border. This situation in most cases exposes the displaced people to some vulnerabilities. Among other classes of displaced people, the most notable groups of concern are refugees and internally displaced persons (IDPs). In contemporary time, conflict is identified to be the primary cause of forced displacement. Since 2009, the Boko Haram insurgency and the counterinsurgency by the Nigerian security forces turned northeast Nigeria into a conflict zone. The crisis has forced more than 2 million people to flee for safety within Nigeria as internally displaced persons (IDPs); while many crossed the border into countries neighbouring Nigeria from the Lake Chad region as refugees. This paper explored and discussed the suffering of the people internally displaced by Boko Haram conflict from the framework of forced displacement. It is found that, the IDPs in Nigeria suffered from multifaceted problems, ranging from the issues of inadequate life-saving assistance, protection related crisis, and the unclear prospect of achieving durable solutions. Moreover, the lack of a clear national policy, institutional, and legal frameworks in addressing internal displacement in Nigeria is found to be the prime cause of the intensification of the plight of IDPs. Thus, it is recommended that, there should be a legally backed national policy on IDPs, which should include punitive measures for corrupt humanitarian officers. Also, provision should be made for effective coordination among national humanitarian agencies. Lastly, a clear rule of engagement between the Government and the international humanitarian agencies should be clearly defined.
\end{abstract}

Keywords: Boko Haram, Forced Displacement, Internally Displaced Persons, Northeast Nigeria

\section{Introduction}

Nigeria is mainly divided along ethnoreligious lines. The northern part of the country is primarily dominated by Muslims who are mostly Hausa or Fulani tribes and some other minority tribes. While the Yoruba and Igbo tribes formed the bulk of the population in south Nigeria; and Christianity is the dominant belief system there. The North is identified to have the lowest human development index in the country. $71.5 \%$ of the northerners live below the international poverty line. The illiteracy rate is as high as $85 \%$; while unemployment stood at $60 \%$. North-east is considered the most backward (Onaedo, Samuel, \& Sejoro, 2017).

The socio-economic reality of the region has its root in the colonial era; amplified by corruption and bad governance. The situation has created a conducive atmosphere for various anti-establishment movements that use religious narratives to gain legitimacy. There was the maitatsine riot in the 1980's in Kano state, the recurrent Shiite-Government clashes, and so many other preaching and sermons by individual scholars that refuted the western oriented and secular system of Nigeria. Boko Haram emerged from this discontentment and turned violent in 2009 (Oyewole, 2017).

Boko Haram was founded by Muhammad Yusuf in Maiduguri of Borno state. The group is officially known as Jama'atu Ahlus Sunnah liddawa'ati wal Jihad. Boko Haram came to limelight in 2009 when it came into violent confrontation with the Nigerian authorities. Following the execution of Yusuf, one of his lieutenant known as Abubakar Shekau took charge of the group and radicalised and sophisticated it further (Agbiboa, 2014). 
Boko Haramism as an ideology is linked directly to the global web of radical Islamists' thinking and discourse. The tenets of Boko Haramism are derived from the mainstream radical Islamist ideological narratives, to which Yusuf is inclined. Boko Haram ideology was based on the principles of rejecting Western education, condemnation of secularism and westernisation, and the incompatibility of Islam with democracy (Raineri \& Martini, 2017).

At the international level, Boko Haram has interacted with some groups outside Nigeria. It is evident in the interaction of Boko Haram with al-Qaeda in the Islamic Maghreb (AQIM), the Movement for Unity and Jihad in West Africa (MUJAO), and Ansar Dine. Mohammed Yusuf considered the founder of al-Qaeda Osama bin Laden a role model worthy of emulation. In 2105, the leader of Boko Haram Abubakar Shekau pledged allegiance to the Islamic State (IS).

As a strategy, Boko Haram prefers always to be on the offensive than defensive. Hence, the Group to use attacks tactics such as ambushes, raids, and assaults against poorly defended targets. Usually, victims of Boko Haram attacks include law enforcement agents, religious and political figures, essential infrastructures, and financial institutions and other business establishments. The strategic objectives of these attacks are to cast distrust of the Government in the minds of the people by making them feel vulnerable and unprotected by the Government (Regens, Mould, Vernon, \& Montgomery, 2016).

\subsection{Internal Displacement}

One of the resultant effects of the Boko Haram conflict is the massive internal displacement of the population within Nigeria. Internal displacement is a situation where persons or group of persons are forcibly uprooted from their homes to other locations within their country as a result of man-induced or natural causes. According to the Internal Displacement Monitoring Centre (IDMC), from 2009 when Boko Haram turned violent, to 2016, almost two and half million people were forced to flee and became internally displaced. Some are in the camps while many others are dispersed across various host communities. An accelerated increase in the number of IDPs was recorded, from about five thousand IDPs in 2009 to approximately 2 and a half million in 2016 ("IDMC » Nigeria IDP Figures Analysis," 2017). This situation has created the worse humanitarian crisis in the history of Nigeria since the Civil War (1967-1970) (Heerten \& Moses, 2017; UNCHR, 2016a)

The IDPs are dispersed across the six states of north-east Nigeria and beyond, with their concentration in Borno state followed by Yobe and Adamawa states and other proximate states in the region such as Taraba, Gombe and Bauchi. All of these states where the IDPs seek shelter, protection and other assistance are also affected by the Boko Haram conflict which led to competition over the inadequate resources between the displaced the host communities (Eweka \& Olusegun, 2016).

\subsection{Causes of Internal Displacement}

In "Internal Displacement: Responsibility and Action", Asplet (2013) identified the major factors that lead to displacement:

\subsubsection{Armed Conflict}

Armed conflict is a situation in which differences between 2 or more states or non-state actors lead to the intervention of armed forces. In most cases due to fear of attacks and as a result of a breakdown of the socioeconomic structures during armed conflict, people are usually left with no option than to flee.

\subsubsection{Generalised Violence}

It is a situation of an indiscriminate spread of violence. Here, there is no specific target. The attack could be perpetrated by or against non-recognised parties to the conflict. This form of unrest usually leaves the population unprotected and vulnerable. Mostly in this situation, fleeing for safety is the only alternative.

\subsubsection{Natural and Man-Made Disasters}

When a disaster happens as a result of natural causes or due to the activities of man, it is called natural or humanmade disaster respectively. Examples of natural disasters are drought, earthquake, tsunamis, and so on; while on the other hands, for instance, human-made disasters could include phenomena related to climate change and so on. It usually causes massive movement of the population.

\subsubsection{Human Rights Violations}

Human rights violations happen when the state or non-state actors infringe on the fundamental rights of some targeted people. The targeting could be on account of race, religion, political reasons, economic rights etc. the victims of human rights violation usually flee in search of protection and respite. 


\subsubsection{Development Projects or Environmental Protection}

Development Projects or Environmental Protection occurs when people are compelled to leave their homes as a result of mega development projects. It happens mostly as a result of the construction of dams, roads, railways, hydroelectric power projects etc. Or for conservation reasons and forestry. These types of projects or policies usually require the vacation of the local population which in most cases exposes the affected people to some vulnerabilities.

\subsection{The Stages of Internal Displacement}

The International Committee of the Red Cross categorised displacement into 4 Major stages: Pre-displacement, Acute displacement, Stable displacement, Durable solutions (International Committee of the Red Cross, 2018).

\subsubsection{Pre-Displacement}

This stage has to do with circumstances that result in displacements such as armed conflict, generalised violence or any other causes that uproot people from their habitual place of residence.

\subsubsection{Acute Displacement}

This stage involves the movement of the displaced persons to a new location other than their original communities. At this phase of displacement, the IDPs usually find themselves in dire need of life-saving assistance and protection.

\subsubsection{Stable Displacement}

This phase of displacement is sometimes referred to as "protracted displacement". Here, the displacement last beyond the reasonable frame of time. IDPs stay for a prolonged period with the host communities, private houses or provided camps.

\subsubsection{Durable Solutions}

This stage is usually considered the last one. Displacement is said to end when durable solutions are achieved for the IDPs. It could be actualised by returning the displaced people to their original homes, or integrating them within the community they found themselves, or to resettle them in other locations in the country other than their original places.

\section{Problem Statement}

Since the escalation of the Boko Haram insurgency into a deadly conflict in 2009, the phenomenon has forced almost 2 and half million people to flee. As a result Nigeria became the country with the highest number of Internally Displaced Persons (IDPs) in sub-Saharan Africa (Norwegian Refugee Council, 2017). The Displacement Tracking Matrix (2017) revealed that women and children formed 79\% of the IDPs population, and children of under 5 years account for $28 \%$. In the same vein, the United Nations Office for the Coordination of Humanitarian Affairs (UNOCHA), further revealed that the IDPs in north-east Nigeria are in desperate need of life-saving assistance such as food and nutrition, healthcare, shelter and non-food items, potable water and improved sanitation and hygiene condition. Also, the education of the IDPs has been reluctantly handled. Again, the IDPs suffer from some protection issues such as Child and Gender-based Violence (CGBV) among others. The prospect of IDPs to return to their original communities is another worrisome issue adding to the plight of these displaced people (UNOCHA, 2018).

However, despite this humanitarian crisis and the suffering of the victims, there is no clear institutional and policy frameworks or legislation that directly and squarely address the plight of the IDPs. Although, the Cluster framework of humanitarian response exist at the international level, but this absence of structures at the national level has retarded the philanthropic efforts of the international actors including the United Nations agencies.

The objective of this paper is to explore and discuss the suffering of the people internally displaced by Boko Haram conflict from the framework of forced displacement; and make policy recommendation that could subdue the situation.

\section{Conceptual Framework}

Forced displacement has been described as "the movements of refugees and internally displaced people (people displaced by conflicts) as well as people displaced by natural or environmental disasters, chemical or nuclear disasters, famine, or development projects" (Migration Data Portal, 2018). The cumulative number of people displaced by the end of the year 2016 globally stood at 65.6 million. Out of this number, 22.5 million are refugees, while 40.3 million are IDPs (UNCHR, 2016b). 
The American Sociologist Eugene Kulischer is credited to have coined the term "Displaced Person." Though, in his work he used the term to refer all classes of people forced to flee - refugees, IDPs, and others; but the contemporary usage of the term is restricted to people that are forcibly displaced from their communities but remain in other locations in their country of nationality (Kumar Panigrahi, 2018).

Forced displacement, whether internal or external is mostly caused by Conflict. Conflicts occur in every region of the globe, and it has been so throughout the history of humankind. Its duration, intensity, dimension differs according to type, cause, and the parties involved. A conflict could happen at the different level of social process and interaction. It could be between individuals, within or between groups, it can also occur within a state or between states and non-state actors. Modern history affirmed that conflict is an integral part of the domestic phenomenon of the modern states. It could manifest in the form of civil wars, insurgencies, inter-ethnic or interreligious clashes. It also happens on the international stage between states or non-state actors.

The phenomenon of forced displacement caused by Boko Haram conflict in northeast revolves around three major components. First, the issue of life-saving assistance; which involves the provision of life-saving and immediate humanitarian needs to the displaced people such as food and nutrition; healthcare; water, sanitation and hygiene (WASH); shelter, and education. The second component is protection. It includes safeguarding IDPs from all forms of human right abuses that could emanate from their vulnerability. Such abuses come in the form of child and gender-based violence (CGBV), trafficking and family separation. Third, is the component of durable solutions. It deals with the long-term remedy of displacement. This component is made up of sub-components of return, resettlement, and local integration. A forcibly displaced person is ceased to considered displaced when he/she achieves durable solutions.

\section{The Plight of Internally Displaced Persons (IDPs) in Northeast Nigeria}

The Boko Haram conflict caused a considerate loss of lives and breakdown of the family structure, destruction of properties and infrastructures, in addition to the absence of the means of livelihood. This situation of fear and insecurity left people with no choice but to migrate (Norwegian Refugee Council, 2017). The deteriorated nature of internal displacement and the suffering of the victims can be analysed from four significant angles. First, on the need for life-saving assistance by the IDPs, the need for protecting them from human rights violations and abuses, the uncertainty of achieving durable solutions; and lastly the absence of a specific national blueprint in addressing the issue.

\subsection{The Life-Saving Assistance}

First, The IDPs are facing severe food insecurity and nutrition problems with global acute malnutrition (GAM) level of $27.3 \%$. Again, 12, 871 children below five years of age were identified to suffer from severe acute malnutrition. In 2013, the Nigerian government made official declaration of emergency on nutrition (Dunn, 2018; UN News, 2016).

Second, in the health sector, most of the medical infrastructural facilities have been closed due to the absence of doctors who fled for security reasons, scarcity of drugs and medical equipment (Sambo, 2017). Reports showed that endemic malaria, acute respiratory infections and watery diarrhoea are critical health concern bedevilling the IDPs; with malaria featuring in 50\% of all the health-related cases in the camps (WHO, 2018). Furthermore, compounding to the health crisis is the problem of water, sanitation and hygiene (WASH). As a result of the trooping of IDPs in camps, the available water and sanitation facilities and structures became inadequate to cater for the basic needs of the IDPs. This lack of WASH increases the risk of the spread of diseases, dehydration and other related ailments (UNICEF, 2016). There is an absence of waste management and inadequate provision of essential utility such as potable water and electric power. This state of poor sanitation and hygiene explained the frequency of the outbreak of diseases such as cholera and related ailments. The IDPs that live outside the camps mostly stayed with host communities or in worship sites such as churches, mosques, and in dilapidated and abandoned buildings that are not humanly habitable (Sambo, 2017).

According to the National Emergency Management Agency, there exist an alarming number of children among the IDPs whom education was truncated by their displacement and a number of them are unaccompanied due to the death of their parents or separation during the conflict. The breakdown of the system of education in northeast Nigeria was accelerated by the destruction of schools, killing and kidnapping of students and teachers by the insurgents. Besides, the usage of school buildings by the displaced population as shelter further affects IDPs education. Moreover, in some camps and communities where the displaced children are accessing education, the quality is poor and far below the standard due to the absence of a conducive environment for teaching and learning and the absence of teaching materials. In most cases, the teaching is done by incompetent volunteer teachers (Abdulazeez, 2016). 


\subsection{The Issue of Protection}

Again, the unsafe condition of the IDPs in northeast exposed them to many protection issues; ranging from exploitations, child and gender-based violence, human trafficking, family separation and detention with no consideration of the rule of law. Moreover, the IDPs are sheltered under the most inhumane condition: overcrowded camps; with few overstretched infrastructural facilities and defective or inadequate non-food items (NFI), such as blankets, buckets, mosquito nets etc. (Obaji \& Alobo, 2016).

\subsection{The Issue of Durable Solutions}

Another issue of concern is that the security forces are gaining ground against the Boko Haram insurgents; but still, the IDPs expressed fear to return to their ravaged communities, as there is no assurance for safety, no clear and sustainable strategy for durable solutions in place for them. On the other hand, other affected populations by the conflict that took refuge in neighbouring countries are voluntarily or forcibly returning to Nigeria. These returnees are likely to out-weight the already inadequate resources and widen the need gaps. As a result, it may add to the suffering of the existing IDPs and returning refugees who are now IDPs (Norwegian Refugee Council, 2017).

\subsection{The Absence of National Humanitarian Response Frameworks}

Despite this humanitarian situation in Nigeria, there is non-existence of legislation, definite and sustainable institutional and policy frameworks in addressing internal displacement. It has impeded national and international humanitarian efforts. It has made planning, implementation, coordination and evaluation of humanitarian efforts difficult. It has also affected the assigning of roles and responsibilities to humanitarian actors, which led to the clash of interests among humanitarian actors, and duplication of duties in some sectors, while others sectors are handled negligibly or inefficiently. Even the draft and yet to be implemented National Policy on internally displaced persons in Nigeria has been discredited for not having any legal status, but a mere outline of policy objectives that are not enforceable (Akuto, 2017; Itumo \& Nwefuru, 2016).

\section{Recommendation}

The Government of Nigeria and humanitarian partners have channeled a considerable amount of resources both human and material in ameliorating internal displacement in northeast Nigeria. However, no commensurate result came out of the effort. Fortunately, the causative factors have been identified by various research conducted academics and professionals in the field. Critical among them is the absence of clear policy, institutional and legal humanitarian frameworks. Therefore, in this paper, it is recommended that:

There should be national policy backed up by legislation that would cater for the prevention, management and to address long-term issues associated with the displacement such as return, resettlement and the integration of IDPs.

Furthermore, the legislation should include punitive measures for corrupt camp and military officials that syphon relief materials and other resources for personal gain at the expense of the victims or take advantage of their vulnerability to abuse them. Mostly, female and children fall victims in this case.

Again, the framework should include definite and clear rules of engagement by the Government to the international humanitarian organisation. Also, there should be institutional centralisation of the national humanitarian agencies to avoid the clash of the interest and duplication of work by various humanitarian agencies of the Government.

\section{Conclusion}

All in all, Boko Haram insurgency and the counter-insurgency by the Nigerian security forces have uprooted almost 2 and half million people from their homes. As a result, Nigeria has the highest number of IDPs in subSaharan Africa. The IDPs mainly suffered from three significant angles. First, they lack the most basic lifesaving assistance, second, they are not adequately protected from abuses and deprivation, more especially the Child, and Gender-Based Violence. Third, is the absence of a definite prospect to achieve durable solutions for the IDPs. All these plights of the IDPs in north-east Nigeria are correlatively related to the lack specific policy, institutional and legal frameworks in addressing the problem. The Government mainly concentrated on ad-hoc efforts in responding to the phenomenon. This momentary approach has made planning, coordination, evaluation and accountability difficult.

\section{Reference}

Abdulazeez, M. (2016). The Boko Haram insurgency and internal dis-placement. State Secretariat for Migration SEM. 
Agbiboa, D. E. (2014). Boko-Haram and the Global Jihad: 'Do Not Think Jihad is Over. Rather Jihad Has Just Begun.' Australian Journal of International Affairs, 68(4), 400-417. https://doi.org/10.1080/10357718.2014.891564

Akuto, G. (2017). Challenges of Internally Displaced Persons ( IDPs ) in Nigeria : Implications for Counselling and the Role of Key Stakeholders, 5(2), 21-27. Retrieved from http://seahipaj.org/journals-ci/june2017/IJIPSD/full/IJIPSD-J-4-2017.pdf

Asplet, M. (2013). Internal Displacement: Responsibility and Action. UNCHR. Retrieved from http://archive.ipu.org/PDF/publications/Displacement-e.pdf

Displacement Tracking Matrix. (2017). Displacement Tracking Matrix: Nigeria Round XV Report 2017. Retrieved from https://data2.unhcr.org/en/documents/download/56254

Dunn, G. (2018). The impact of the Boko Haram insurgency in Northeast Nigeria on childhood wasting: a doubledifference study. Conflict and Health, 12(1), 6. https://doi.org/10.1186/s13031-018-0136-2

Eweka, O., \& Olusegun, T. O. (2016). Management of Internally Displaced Persons in Africa: Comparing Nigeria and Cameroon. African Research Review, 10(1), 193. https://doi.org/10.4314/afrrev.v10i1.15

Heerten, L., \& Moses, A. D. (2017). Postcolonial Conflict and the Question of Genocide. Routledge. https://doi.org/10.4324/9781315229294

ICRC. (2018). Addressing Internal Displacement in Times of Armed Conflict and Other Violence | International Committee of the Red Cross. Retrieved April 6, 2018, from https://www.icrc.org/en/publication/0867internally-displaced-humanitarian-response-internally-displaced-people-armed

IDMC » Nigeria IDP Figures Analysis. (2017). Retrieved April 6, 2018, from http://www.internaldisplacement.org/sub-saharan-africa/nigeria/figures-analysis

Itumo, A., \& Nwefuru, H. (2016). Nigerian State and Responses to Plights of Persons Internally Displaced by Boko Haram Insurgents: Implications for Socio-Economic and Political Development. Research on Humanities and Social Science, 6(15), 24-38.

Kumar Panigrahi, S. (2018). Development, Displacement and Rehabilitation: Indispensably Inter-Related. IOSR Journal Of Humanities And Social Science, 23(7), 79-87. https://doi.org/10.9790/0837-2303077987

Migration Data Portal. (2018). Forced migration or displacement | Migration data portal. Retrieved April 6, 2018, from https://migrationdataportal.org/themes/forced-migration-or-displacement

Norwegian Refugee Council. (2017). New study: Displaced Nigerians too scared to return home | NRC. Retrieved April 6, 2018, from https://www.nrc.no/news/2017/october/displaced-nigerians-too-scared-to-return-home/

Obaji, S., \& Alobo, E. (2016). Internal Displacement in Nigeria and the Case for Human Rights Protection of Displaced Persons. Journal of Law, Policy and Globalization, 51(0), 26-33. Retrieved from http://www.iiste.org/Journals/index.php/JLPG/article/view/32031

Onaedo, E., Samuel, O., \& Sejoro, J. (2017). An Assessment of the Impact of Internal Displacement on Human Security in Northern Nigeria, 10(1), 42-65.

Oyewole, S. (2017). Making the Sky Relevant to Battle Strategy: Counterinsurgency and the Prospects of Air Power in Nigeria. Studies in Conflict \& Terrorism, 40(3), 211-231. https://doi.org/10.1080/1057610X.2016.1188533

Raineri, L., \& Martini, A. (2017). ISIS and Al-Qaeda as Strategies and Political Imaginaries in Africa: A Comparison between Boko Haram and Al-Qaeda in the Islamic Maghreb. Civil Wars, 19(4), 425-447. https://doi.org/10.1080/13698249.2017.1413226

Regens, J. L., Mould, N., Vernon, E., \& Montgomery, A. (2016). Operational Dynamics of Boko Haram's Terrorist Campaign Following Leadership Succession. Social Science Quarterly, 97(1), 44-52. https://doi.org/10.1111/ssqu.12251

Sambo, A. S. (2017). Internal Displaced Persons and Their Information Needs. Library Philosophy and Practice. Retrieved from http://digitalcommons.unl.edu/libphilprac

UN News. (2016). "Alarming" levels of malnutrition and famine-like conditions in north-east Nigeria - UN | UN News. Retrieved April 6, 2018, from https://news.un.org/en/story/2016/07/534202-alarming-levelsmalnutrition-and-famine-conditions-north-east-nigeria-un

UNCHR. (2016a). News - Boko Haram: Humanitarian crisis in North East 'terribly worse'-UN. Retrieved April 
6, 2018, from http://data2.unhcr.org/en/news/12310

UNCHR. (2016b). UNHCR Global Trends Forced displacement in 2016. Retrieved April 6, 2018, from http://www.unhcr.org/globaltrends2016/

UNICEF. (2016). UNICEF Nigeria - Water, Sanitation and Hygiene - Providing lifesaving interventions in water, sanitation and hygiene for internally displaced persons in north east Nigeria. Retrieved April 7, 2018, from https://www.unicef.org/nigeria/wes_10558.html

UNOCHA. (2018). About OCHA Nigeria | OCHA. Retrieved April 6, 2018, from http://www.unocha.org/nigeria/about-ocha-nigeria

WHO | Malaria campaign saving young lives in Nigeria. (2018). WHO. Retrieved from http://www.who.int/malaria/news/2017/emergency-borno-state/en/

\section{Copyrights}

Copyright for this article is retained by the author(s), with first publication rights granted to the journal.

This is an open-access article distributed under the terms and conditions of the Creative Commons Attribution license (http://creativecommons.org/licenses/by/4.0/). 